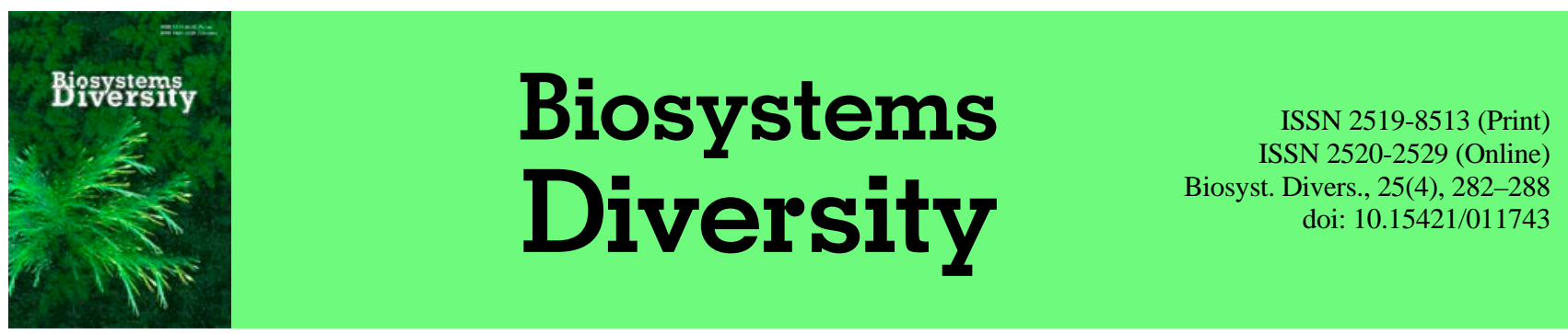

\title{
Ecology of seed germination and features of ontogeny of floating mat-forming hygrogelophyte Calla palustris (Araceae) under laboratory conditions
}

\author{
E. A. Belyakov****, A. G. Lapirov*, O. A. Lebedeva* \\ *Papanin Institute for Biology of Inland Waters, Borok, Russia \\ **Cherepovets State University, Cherepovets, Russia
}

\section{Article info}

Received 12.10.2017

Received in revised form 17.11.2017

Accepted 19.11.2017

Papanin Institute for Biology of Inland Waters RAS, Borok, Yaroslavl oblast, 152742, Russia. Tel.: +48-547-24-042

E-mail:

eugenybeliakov@yandex.ru, lapir@ibiw.yaroslavl.ru

Cherepovets State University, Lunacharsky Ave., 5 ,

Cherepovets, Vologda oblast 162600, Russia.
Belyakov, E. A., Lapirov, A. G., \& Lebedeva, O. A. (2017). Ecology of seed germination and features of ontogeny of floating mat-forming hygrogelophyte Calla palustris (Araceae) under laboratory conditions. Biosystems Diversity, 25(4), 282-288. doi:10.15421/011743

This article examines the ecology of germination and the features of ontogenesis of the floating mat-forming hygrogelophyte Calla palustris L. in the territory of some regions in the central part of European Russia and the Republic of Belarus under laboratory conditions. It has been found that in the surveyed territory in the dense ear-like collective fruit of $C$. palustris, $40.7 \pm 6.4$ fruits, juicy berries, are formed and the number of seeds produced (actual seed productivity), averages $164.0 \pm 89.3$. Widely varying data on the number of berries in the collective fruit, as well as a variable number of ovules in them, shows that the seed productivity of C. palustris depends on a whole range of endogenous and exogenous factors, including the effectiveness of pollination of flowers by insects. In laboratory experiments, various storage periods ( 2 and 12 months) and methods of presowing seed treatment (stratification, drying, ice-freezing) were applied to simulate the ecological conditions of the growth of white alder. It is shown that freshly harvested seeds do not germinate at once, and wet cold stratification makes it possible to achieve maximum values of laboratory germination (from 84.4 to 99.0) and germination energy (from 66.6 to 88.3). Given that the features of germination are indicators of dormancy, it is demonstrated that seeds of C. palustris are in a state of shallow physiological dormancy, conditioned by the physiological mechanism of inhibition. Along with dry storage, wet cold stratification is the main way for seeds to enter a non-dormant state. Such mechanisms are consistent with the climatic features of the regions in which the species grows. It is found that $C$. palustris seeds, in common with many other species of hygrogelophytes, can float on the water surface for a long time (more than 30 days), spreading with water flow (hydrochoria). Seeds of $C$. palustris are photosensitive, germination is observed in a wide range of temperatures from $10-14$ to $30^{\circ} \mathrm{C}$ (at constant humidity), type of germination - underground (hypogeal). It is found that ontogeny of individuals of generative origin of $C$. palustris in the laboratory is terminated (the plants died after passing the juvenile ontogenetic state). The formation of $C$. palustris seedlings under laboratory conditions lasts 23-25 days and is characterized by the appearance of the main organs of the plant and the anisotropic growth of the shoot axis. At the final stage of development, the seedling is represented by a uniaxial monopodial and anisotropic growing rosette shoot with shortened internodes. The juvenile ontogenetic state in laboratory conditions lasts up to 7 months, after which the plants die off. In the framework of ontomorphogenesis, the stages of ontogenetic development under study (the seedling and the juvenile plant) correspond to the phase of the primary uniaxial rosette shoot. The plant in this period is represented by a uniaxial monopodially growing anchorage shoot. The detection of virgin plants in natural conditions indicates the possibility of their further development from the rudiments of generative origin. The main way of the species reproduction is vegetative, characteristic of most aquatic and semi-aquatic plants. In the course of ontogenesis, progressive features of development such as cotyledon greening and early death of the radicle root have been revealed.

Keywords: ecology of germination; type of seed dormancy; seed productivity; features of ontogeny

\section{Экология прорастания семян и особенности онтогенеза сплавинообразующего гигрогелофита Calla palustris (Araceae) в лабораторных условиях}

\author{
Е. А. Беляков*,**, А. Г. Лапиров*, О. А. Лебедева* \\ *Институт биологии внутренних вод имени И. Д. Папанина РАН, Борок, Россия \\ **Череповеикий государственный университет, Череповеи, Россия
}

В лабораторных условиях рассмотрены экология прорастания и особенности онтогенеза сплавинообразующего гигрогелофита Calla palustris L. с территории ряда областей европейской части России и Республики Беларусь. В составе плотного початковидного соплодия C. palustris на территории исследуемого региона формируется $40,7 \pm 6,4$ плодов - сочных ягод, а число образованных семян (фактическая 
семенная продуктивность) в среднем достигает 164,0 \pm 89,3. Широко варьирующие данные по числу ягод в соплодии, как и непостоянное число семяпочек в них показывает, что семенная продуктивность C. palustris зависит от целого комплекса эндогенных и экзогенных факторов, в том числе эффективности опыления цветков насекомыми. В лабораторных экспериментах для моделирования экологических условий произрастания белокрыльника применены различные сроки хранения (2 и 12 месяцев) и методы предпосевной обработки семян (стратификация, высушивание, вмораживание в лед). Свежесобранные семена сразу не прорастают, а влажная холодная стратификация позволяет достичь максимальных величин лабораторной всхожести (от 84,4 $\pm 1,4$ до 99,0 $\pm 1,0$ ) и энергии прорастания (от 66,6 $\pm 2,2$ до 88,3 \pm 5,7). Учитывая, что особенности прорастания являются индикаторами покоя, выяснили, что семена C. palustris находятся в состоянии неглубокого физиологического покоя, обусловленного физиологическим механизмом торможения. Наряду с сухим хранением основным способом выхода семян из состояния покоя является влажная холодная стратификация. Подобные механизмы согласуются с климатическими особенностями регионов произрастания данного вида. Семена белокрыльника болотного, как и многих других видов гигрогелофитов, могут длительное время (более 30 суток) держаться на поверхности воды, распространяясь при помощи водного потока (гидрохория). Семена C. palustris светочувствительны, прорастание наблюдается в широком спектре температур - от $10-14$ до $30{ }^{\circ} \mathrm{C}$ (при постоянной влажности), тип прорастания - подземное (гипогеальное). Онтогенез особей генеративного происхождения C. palustris в лабораторных условиях - обрывающийся (растения погибали, пройдя ювенильное онтогенетическое состояние). Формирование проростка у C. palustris в лабораторных условиях длится 23-25 суток и характеризуется появлением основных органов растения и анизотропным нарастанием побеговой оси. На завершающем этапе развития проросток представлен одноосным моноподиально и анизотропно нарастающим розеточным побегом с укороченными междоузлиями. Ювенильное онтогенетическое состояние в лабораторных условиях у растений длится до 7 месяцев, после чего растения отмирают. В рамках онтоморфогенеза рассмотренные этапы онтогенетического развития (проросток и ювенильное растение) соответствуют фазе первичного одноосного розеточного побега. Растение в этот период представлено одноосным моноподиально нарастающим побегом закрепления. Обнаружение в природных условиях виргинильных растений говорит о возможности их дальнейшего развития из зачатков генеративного происхождения. Основным способом размножения этого вида является вегетативное, характерное для большинства водных и прибрежно-водных растений. В ходе онтогенеза выявлены прогрессивные черты развития - позеленение семядоли и раннее отмирание главного (зародышевого) корня проростка.

Ключевые слова: экология прорастания; тип покоя семян; семенная продуктивность; особенности онтогенеза

\section{Введение}

В настоящее время исследования в области репродуктивной биологии растений являются одними из самых динамично развивающихся (Barrett, 2010). Рассеивание пропагул в подходящие условия и их последующее прорастание - два основных процесса, влияющих на структуру растительного сообщества (Kalamees and Zobel, 2002). Формирование растений из мобильных семян может обеспечить будущее существование сообщества в изменяющихся условиях окружающей среды (Nilsson et al., 2010). Вопросам прорастания семян до сих пор уделяется мало внимания (van Leeuwen et al., 2014).

Ароидные, или Аронниковые (Araceae Juss.) - одно из древних и наиболее крупных семейств однодольных растений, включающее в себя весьма разнообразные по характеру местообитаний и жизненным формам таксоны, встречающиеся на всех континентах, кроме Антарктиды (Cabrera et al., 2008; Nugroho and Santika, 2008; Cusimano et al., 2011; Nauheimer et al., 2012; Henriquez et al., 2014). По современным данным, в состав семейства входят 3790 видов из 118 родов (Nauheimer et al., 2012; Henriquez et al., 2014). Основной угрозой для выживания многих видов этой таксономической группы является потеря и сокращение естественной среды их обитания (Nugroho and Santika, 2008).

Белокрыльник болотный (Calla palustris L., род Calla L.) - широко распространенный в циркумбореальной области вид, являющийся единственным представителем подсемейства Calloideae (Barabé and Labrecque, 1983) Scribailo and Tomlinson, 1992; Cabrera et al., 2008; Ulrich et al., 2013). Это растение относится к сплавинообразующим гигрогелофитам - особой группе длиннопобеговых и полурозеточных растений с плагиотропными побегами (Vishnitskaya, 2009). Именно эта группа растений (наряду с другими видами, такими как Comarum palustre L. и Menyanthes trifoliate L.), способствует формированию и поддержанию болотных и гигрофильных сообществ, возникающих в результате процессов сплавинообразования (Vishnitskaya, 2009). C. palustris произрастает по топким берегам водохранилищ, озер и рек, прудов и канав, а также по влажным ольшаникам, осоковым и моховым болотам, по окрайкам низинных болот (дистрофные воды) (Efremov and Alekseev, 1983; Vishnitskaya, 2009). За счет активного вегетативного разрастания белокрыльник формирует значительные по площади заросли, в которых нередко может выступать в качестве доминанта. В качестве сопутствующих видов в сообществах с белокрыльником участвуют Lysimachia thyrsiflora L., Alisma plantago-aquatica L., Lythrum salicaria L., Cicuta virosa L., Typha latifolia L., Carex acuta L., а также Comarum palustre и Menyanthes trifoliate. Вид чутко реагирует на колебания уровня воды в местообитаниях, выпа- дая из травостоя. В настоящее время белокрыльник болотный охраняется в некоторых регионах России (Воронежская обл., Алтайский край (Hlyzova, 2011; Silanteva, 2016) и ряде других территорий), которые располагаются вблизи либо на южной границе ареала C. palustris.

Большинство отечественных и зарубежных публикаций по C. palustris посвящены цитологическим исследованиям, вопросам побегообразования, онтоморфогенезу, вегетативному размножению и сезонному развитию (Dudley, 1937; Eber, 1983; Scribailo and Tomlinson, 1992; Vishnitskaya, 2009; Rudskiy et al., 2011; Sarneel, 2013). Сведения о воздействии экологических факторов на процесс прорастания семян и семенную продуктивность вида в отечественной и зарубежной литературе малочисленны и носят фрагментарный характер (Didley, 1937; Hutchinson, 1975; Barabé and Labrecque, 1983; Efremov and Alekseev, 1983; Vishnitskaya, 2009; Godefroid et al., 2010; van Leeuwen et al., 2014). Последний тезис относится и к материалам по онтогенезу этого вида (Didley, 1937; Efremov and Alekseev, 1983; Vishnitskaya, 2009).

Цель этой статьи - обобщить экологию прорастания семян C. palustris и особенности онтогенеза этого вида из зачатков генеративного происхождения в лабораторных условиях.

\section{Материал и методы исследований}

Полевые материалы собраны авторами в 2014-2016 гг. (с конца июля по начало сентября) в естественных местах обитания С. palustris в Ярославской (Ростовский р-н: оз. Чашницкое, 56,938463 N, 39,383724 Е и оз. Рюмниковское, 56,970353 N, 39,389561 E; Пошехонский р-н: Талицкое верховое болото, 58,737310 N, 38,763885 Е), Московской (Шатурский р-н: оз. Белое, 55,247732 N, 39,993948 Е), Тверской (Осташковский р-н: оз. Сиг, 57,054060 N, 33,184258 Е) областях и Республике Беларусь (Минская обл.: оз. Млынок, 54,827504 N, 26,903012 Е; о3. Белое, 54,825639 N, 26,843540 Е; оз. Запортово, 54,832855 N, 26,938031 Е). Всего у растений проанализировано более 50 соплодий. Для характеристики фактической семенной продуктивности (ФСП) (Vaynagiy, 1974 - цит. по Lapirov et al., 2017) определяли: число ягод в соплодиях, число семян в ягоде и общее число семян в соплодии.

Опыты по прорастанию проводили с семенами, собранными в 2015 и 2016 гг. в Ярославской и Тверской обл. Условия хранения и предварительная предпосевная обработка семян представлены в таблице 1 . Во время хранения при низкой положительной температуре в холодильнике (влажная холодная стратификация - ВХС) семена были полностью покрыты отстоявшейся водопроводной водой. Высушивание семян в течение 1 часа проводили при комнатной температуре, предварительно обсушив их фильтровальной 
бумагой, вмораживание в лед - в морозильной камере при темпеpaтуре $-8^{\circ} \mathrm{C}$. Кроме того, семена белокрыльника, собранные в 2015 г. в Ярославской обл. (Пошехонский р-н, Талицкое верховое болото), были подвергнуты разным срокам стратификации (от 4,3 месяца до двух лет). Во всех экспериментах семена C. palustris проращивали в люминостате (освещенность - 1200-1 500 лк, фотопериод $-9 / 15$, температура $\left.-+23^{\circ} \mathrm{C}\right)$, в чашках Петри на фильтровальной бумаге, увлажненной отстоявшейся водопроводной водой. Во всех вариантах опытов использовали три чашки Петри по 50 семян в каждой.

\section{Таблица 1}

Влияние особенностей хранения и предпосевной обработки семян C. palustris на основные показатели прорастания

\begin{tabular}{|c|c|c|c|c|c|c|}
\hline \multirow{2}{*}{$\begin{array}{l}\text { Дата и место } \\
\text { сбора семян }\end{array}$} & \multirow{2}{*}{$\begin{array}{c}\text { Сроки и } \\
\text { особенности } \\
\text { хранения семян }\end{array}$} & \multirow{2}{*}{$\begin{array}{l}\text { Характер и продолжительность } \\
\text { предпосевной обработки семян }\end{array}$} & \multicolumn{4}{|c|}{ Основные показатели прорастания } \\
\hline & & & $\begin{array}{l}\text { лаг-время, } \\
\text { сут. }\end{array}$ & $\begin{array}{l}\text { период про- } \\
\text { растания, сут. }\end{array}$ & $\begin{array}{c}\text { энергия } \\
\text { прорастания, \% }\end{array}$ & $\begin{array}{l}\text { лабораторная } \\
\text { всхожесть, \% }\end{array}$ \\
\hline \multirow{4}{*}{$\begin{array}{c}\text { Эксперимент 1: } \\
\text { 05.09.2015 г., ЯО, ПР, } \\
\text { Талицкое верховое } \\
\text { болото }\end{array}$} & \multirow{4}{*}{12 мес. ВXC } & ВХС в течение 40 сут. & $11,5 \pm 1,5^{\circ}$ & $1,0 \pm 0,0^{\circ}$ & $1,0 \pm 0,0^{*}$ & $2,2 \pm 1,4^{\circ}$ \\
\hline & & $\begin{array}{l}\text { высушивание, затем содержание в } \\
\text { холодильнике в течение } 40 \text { сут. }\end{array}$ & $8,0 \pm 0,0$ & $5,3 \pm 0,4$ & $5,5 \pm 3,0$ & $18,8 \pm 6,0$ \\
\hline & & $\begin{array}{l}\text { высушивание, затем содержание при } \\
\text { комнатной температуре в течение } 40 \text { сут. }\end{array}$ & $8,0 \pm 0,0$ & $4,3 \pm 1,5$ & $7,7 \pm 3,7$ & $25,5 \pm 6,0$ \\
\hline & & вмораживание в лед в течение 40 сут. & $6,0 \pm 0,0^{\circ}$ & $9,0 \pm 2,6^{\circ}$ & $32,1 \pm 9,6^{\circ}$ & $48,8 \pm 5,2^{\circ}$ \\
\hline \multirow{4}{*}{$\begin{array}{c}\text { Эксперимент 2: } \\
\text { 09.08.2016 г., ТО, ОР, } \\
\text { верховое болото, } \\
\text { примыкающее к } \\
\text { оз. Сиг }\end{array}$} & \multirow{4}{*}{2 мес. BXC } & ВХС в течение 40 сут. & $6,6 \pm 0,4$ & $9,6 \pm 1,0$ & $6,6 \pm 2,2$ & $78,8 \pm 3,0^{\circ}$ \\
\hline & & $\begin{array}{l}\text { высушивание, затем содержание в } \\
\text { холодильнике в течение } 40 \text { сут. }\end{array}$ & $7,5 \pm 0,5$ & $3,5 \pm 0,5^{\circ}$ & $10,0 * *$ & $93,2 \pm 4,4^{\circ}$ \\
\hline & & $\begin{array}{l}\text { высушивание, затем содержание при } \\
\text { комнатной температуре в течение } 40 \text { сут. }\end{array}$ & $7,0 \pm 0,0$ & $5,3 \pm 0,4^{\bullet}$ & $6,6 \pm 4,4$ & $87,7 \pm 1,5^{\circ}$ \\
\hline & & вмораживание в лед в течение 40 сут. & $6,6 \pm 1,1$ & $9,6 \pm 0,4$ & $5,5 \pm 3,7$ & $61,1 \pm 3,7^{*}$ \\
\hline
\end{tabular}

Примечание: * - проросло 1 семя на 9-е сутки, ** - семена проросли в одной чашке из трех; ЯО - Ярославская обл., ПР - Пошехонский р-н, ТО - Тверская обл., $\mathrm{OP}-$ Осташковский $\mathrm{p}-\mathrm{H}$. - -значение в рамках конкретного эксперимента по различным показателям прорастания достоверно отличается от остальных при $\mathrm{P}<0,05$.

Для характеристики процесса прорастания использовали следующие основные показатели: лаг время - время в днях между началом эксперимента и началом прорастания; конечное прорастание - процент проросших семян в конце эксперимента; энергия прорастания - процент проросших семян в течение 7 дней; период прорастания - количество дней, в течение которых семена прорастают (Belyakov and Lapirov, 2015). В работе применяли онтогенетический и сравнительно-морфологический (Savinykh and Cheryomushkina, 2015) методы исследования, используемые при изучении водных и прибрежно-водных растений.

Изучение начальных этапов онтогенеза особей генеративного происхождения проводили в лабораторных условиях. Использовали проростки, полученные из семян, собранных в 2015 г. в Ярославской обл. (хранение - 4,3 мес. ВХС). Одну часть проростков оставляли развиваться в чашках Петри, другую сажали в эксикаторы на $1 / 3$ заполненные песком, в воду на глубину до 1,0-1,5 cм.

В ходе эксперимента у растений фиксировали появление первичного (зародышевого) корня, формирование адвентивных корней, образование первого и второго настоящих листьев. Кроме того, проводили подробный морфологический анализ отдельных элементов надземной и подземной сферы на начальных этапах развития проростка. Для измерения основных морфометрических показателей проростков использовали бинокулярные микроскопы МБС-10 и МСП-2, снабженные микрометрическими шкалами. Все данные статистически обработаны и сведены в таблицы, в которых представлены средние показатели и отклонения от средней.

Статистический анализ проводили средствами пакета Statistica 6.1 (StatSoft Inc., USA). Данные представляли в виде x \pm SD. Для сравнения двух независимых выборок использовали t-критерий Стьюдента (при $\mathrm{P}<0,05$ различия считали достоверными, предварительно проверив данные на нормальность распределения). Для показателей прорастания объем выборки составил три повторности в каждом эксперименте.

\section{Результаты}

Время цветения C. palustris в Европейской части России - конец мая - начало июня, созревание плодов наблюдается в конце июля - сентябре. Плод белокрыльника паракарпный, многосемянный, представляющий собой сочную верхнюю ягоду (до $1,3 \pm$ 0,8 см в диаметре, высотой до 0,8-1,0 см) ярко-красного цвета, заполненную прозрачным студенистым содержимым. Ягоды, в свою очередь, собраны в плотное початковидное соплодие (Levina, 1981), длиной 4,0 $\pm 0,6$ см, диаметром $2,4 \pm 0,4$ см. В составе соплодия у C. palustris, по нашим подсчетам, находится 40,7 $\pm 6,4$ (max. -60; min. -26) сочных ягод. Число семян в ягоде - величина переменная (в среднем, $4,0 \pm 0,4$ ). Анализ показал, что данные по семенной продуктивности (в расчете на одно плотное соплодие) у растений из Ярославской обл. (число ягод в початке $-49,0 \pm 4,0$, число семян в ягоде $-5,1 \pm 2,7$, число семян в початке $-251,6 \pm$ $89,8)$, достоверно не отличаются от таковых из других исследованных регионов (Тверская и Московская обл., Республика Беларусь). Так, у растений из Тверской и Московской обл. среднее число семян в початке достигало $145,0 \pm 55,2$, а из Республики Беларусь $136,0 \pm 86,1$. Между тем, нами обнаружены единичные соплодия, число семян в которых значительно превышало указанные выше пределы (327-405).

По нашим наблюдениям, процесс диссеминации у белокрыльника растянут. К началу осени цветонос полегает на влажный грунт или мох, плоды от разбухания студенистой прозрачной массы лопаются, что и приводит к высвобождению семян (Efremov and Alekseev, 1983). Зрелые семена белокрыльника гладкие, блестящие, продолговато-овальные, светло-коричневые, с 12-13 продольными темно-коричневыми полосками. На конце семени у C. palustris хорошо заметны пятна темного цвета, имеющие губчатую структуру (Dudley, 1937). Длина семени (0,42 $\pm 0,01$ мм) обычно в два раза больше его диаметра ( $0,20 \pm 0,01$ мм). Семенная оболочка плотная, твердая, с воздухоносными полостями и восковым налетом, благодаря чему семена белокрыльника болотного могут длительное время держаться на поверхности воды, распространяясь при помощи водного потока (гидрохория) (Efremov and Alekseev, 1983; Leeuwen et al., 2014). По нашим наблюдениям, ceмена могут сохранять плавучесть в течение более чем 30 суток. Сбоку семени имеется шов, образующий продольную борозду, внутри которой располагается сосудистый пучок (Dudley, 1937). Внутри семени - обильный эндосперм и крупный, содержащий хлорофилл, ланцетовидный по форме зародыш, дифференцированный на трубковидную семядолю, зародышевый корешок и зародышевую почечку (Dudley, 1937; Efremov and Alekseev, 1983; Nikolaeva et al., 1999). Под экологией прорастания мы, следуя P. Е. Левиной (Levina, 1981, p. 61), понимаем «диапазон и совокупность всех факторов среды, необходимых и неизбежно сопутствующих прорастанию». Анализ экспериментов показал, что свежесобранные семена C. palustris сразу не прорастают. Основным способом выхода семян C. palustris из состояния покоя является влажная холодная стратификация. Исследование динамики основных показателей прорастания семян после различных сроков влажной холодной стратификации (рис. 1) показало, что своего 
максимума величины лабораторной всхожести и энергии прорастания они достигают к 10-му месяцу хранения. При этом лагвремя на всем протяжении эксперимента существенным образом не изменяется. К концу эксперимента показатель вырос в два раза, что обусловлено резким снижением лабораторной всхожести семян. Способность семян C. palustris к прорастанию при ВХС ограничена 1,5-2,0 годами. Подобное обнаружено нами и для семян, собранных на территории Московской области.

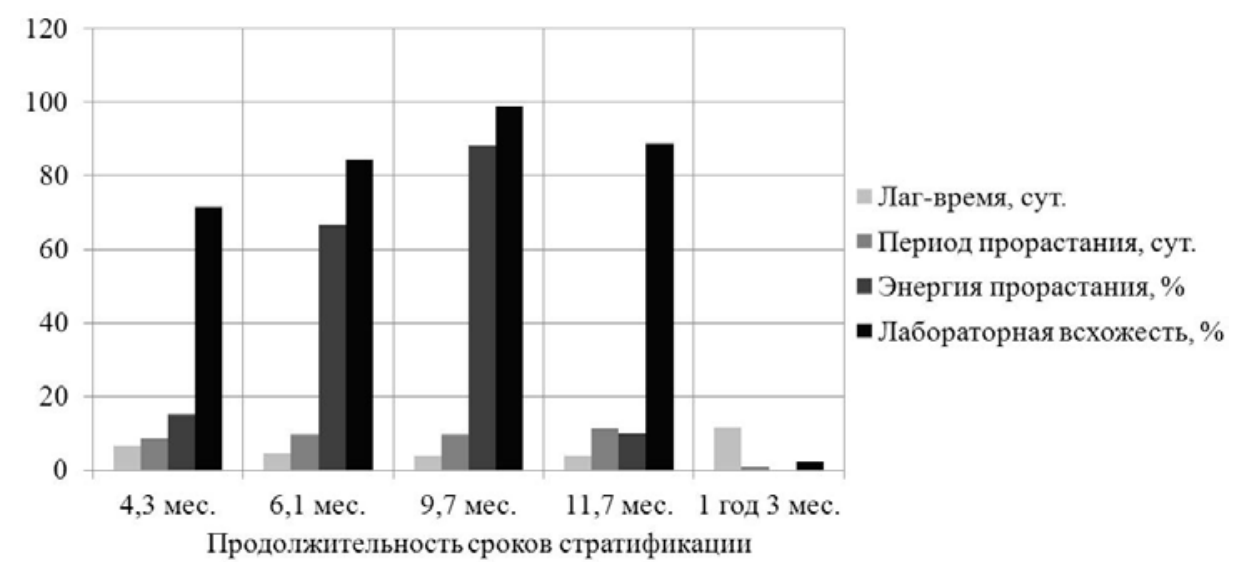

Pис. 1. Динамика основных показателей прорастания семян C. palustris,

собранных на территории Ярославской обл., при разных сроках влажной холодной стратификации

Различные способы предпосевной обработки (табл. 1) применены для моделирования возможных экологических условий, возникающих при прорастании семян в Ярославской и Тверской областях. При этом у семян, собранных в Ярославской обл. (эксперимент 1, табл. 1), наибольшие величины самых важных показателей - лабораторной всхожести и энергии прорастания - получены при вмораживании семян в лед при самом низком (из всех обработок) лаг-времени. Все это говорит о том, что при резком возврате холодов в весенний период семена белокрыльника способны сохранить жизнеспособность и прорасти в короткий период. Высокие показатели лабораторной всхожести (61-93\%), получены для семян из Тверской обл. (эксперимент 2, табл. 1) при всех способах предпосевной обработки. При этом здесь нами отмечены низкие величины энергии прорастания.

Как показали наблюдения, семена белокрыльника при прорастании не ослизняются. Прорастание семян C. palustris наблюдается в широком спектре температур - от 10 до $30^{\circ} \mathrm{C}$. Семена белокрыльника светочувствительны, в процессе прорастания требуют постоянной влажности, тип прорастания - подземное (гипогеальное). Рассмотрим начальные этапы онтогенеза особи генеративного происхождения и его особенности.

Проросток. Данное онтогенетическое состояние у C. palustris в лабораторных условиях длится в течение 23-25 сут. Характеризуется появлением всех основных органов растения и анизотропным нарастанием побеговой оси. Прорастание семян происходит следующим образом. Период набухания у свежесобранных семян C. palustris в экспериментах длится до 4-5 суток, после чего зародышевый корешок прорывает покровы семени. При дальнейшем росте базальная часть семядоли с зародышевым корешком проходит через микропилярное отверстие. Рост семядоли продолжается до того момента, пока развивающееся растение не будет располагаться перпендикулярно продольной оси семени. При этом апикальный конец семядоли остается в эндосперме, выполняя при этом гаусториальную функцию. К концу первых суток после начала прорастания проросток представлен семядолей с хорошо выраженным в ее базальной части влагалищем, внутри которого располагается почечка зародыша, и слабо дифференцированным гипокотилем, переходящим в зародышевый корешок. На третьи сутки, вместе с ростом главного корня, через влагалище семядоли пробивается первый лист. Его рост и постепенное развертывание наблюдается в течение двух суток, максимальных размеров он достигает на 4-5-е сутки. Листовая пластинка нежно-зеленого цвета, простая, продолговато-ланцетовидная с хорошо выраженным продольным жилкованием, плавно переходящая в тонкий расширенный длинный черешок. В этот период, по нашим наблю- дениям, место перехода гипокотиля в зародышевый корешок характеризуется зубчатым «венцевидным утолщением». На более поздних этапах развития граница между гипокотилем и главным корнем выражена слабо. На 11-12-е сутки происходит развертывание второго ассимилирующего листа, отличающегося от первого более широкой листовой пластинкой (рис. 2). Главный корень в этот период нередко достигает максимальных размеров, также отмечено появление первого придаточного корня. Эти корни не несут корневых волосков. На 15-18-е сутки развертывается третий лист, идентичный по характеристикам второму.

Таким образом, на завершающем этапе развития проросток представлен одноосным моноподиально и анизотропно нарастающим розеточным побегом с укороченными междоузлиями (табл. 2). Число листьев достигает трех, придаточный корень - один, либо они отсутствуют. Главный корень сохраняется, либо, у части растений, прекращает свое развитие и отмирает. Емкость верхушечной почки - три - четыре листовых зачатка. На этом этапе все растения, выращиваемые нами в чашках Петри, отмирали. О гибели проростков на этой стадии развития указывали многие исследователи (Didley, 1937; Efremov and Alekseev, 1983; Vishnitskaya, 2009).

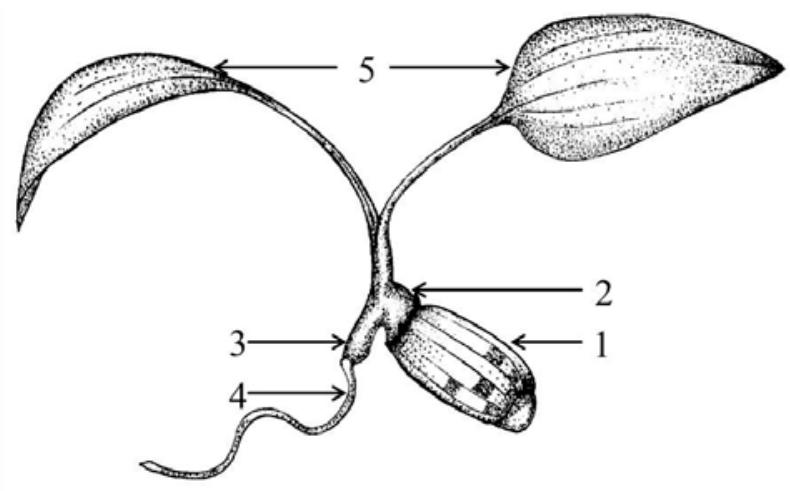

Pис. 2. Проросток Calla palustrus на стадии двух листьев (11-12 сут.): 1 - семя, 2 - семядоля, 3 - гипокотиль, 4 - главный корень, 5 - ассимилирующие листья

Отметим, что в эксикаторе и в чашках Петри развитие растений до стадии проростка происходило синхронно. Поэтому, после гибели растений в чашках Петри, дальнейшее наблюдение за начальными этапами онтогенеза C. palustris было продолжено на растениях, выросших в эксикаторе.

Ювенильное онтогенетическое состояние в лабораторных условиях у растений длилось до 7 мес., после чего растения также 
отмирали. К 35-40-м суткам происходило развертывание четвертого ассимилирующего листа (с сердцевидной листовой пластинкой, рис. 3) и отмирание первого, а к 50-58-м суткам появление пятого листа (тоже с сердцевидной листовой пластинкой) и отмирание второго. В этот же период практически у всех растений уже сформировался первый придаточный корень. Емкость верхушечной почки осталась без изменений.

Таблица 2

Основные морфологические показатели элементов побеговой сферы проростка C. palustris

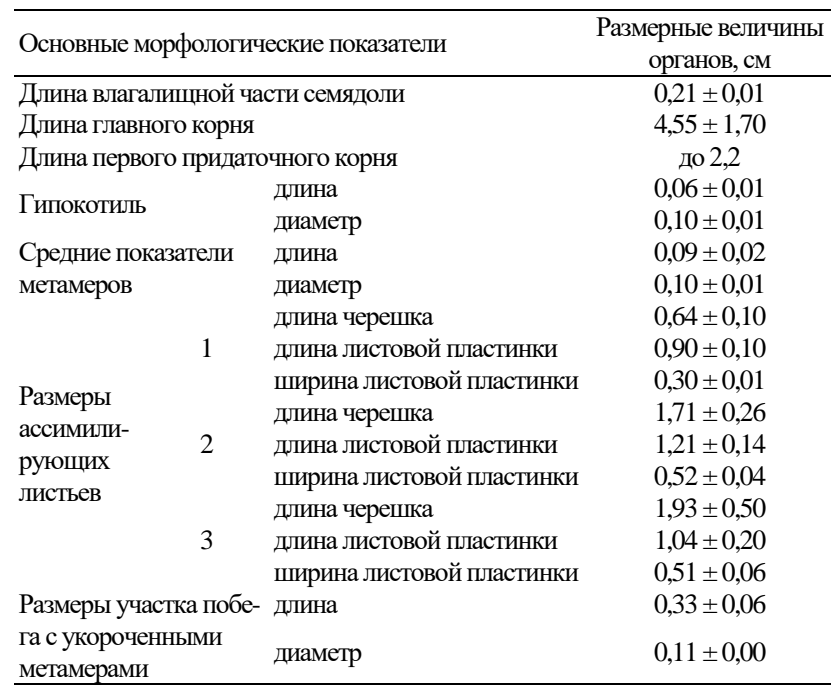

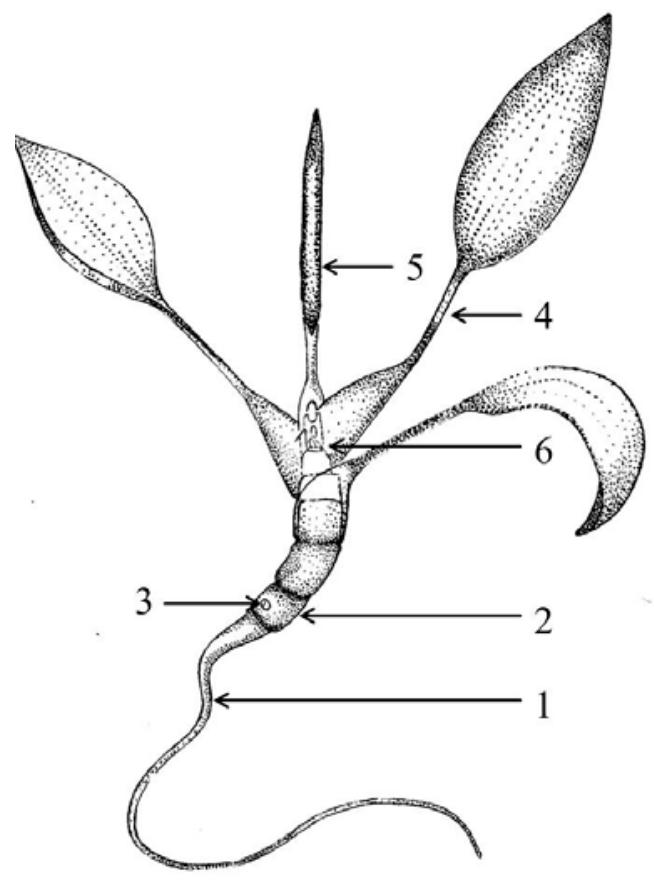

Рис. 3. Ювенильное растение C. palustrus (35-40 сут. после прорастания): 1 - главный корень, 2 - гипокотиль, 3 - развивающийся придаточный корень, 4 - развернувшийся ассимилирующий лист, 5 - не развернувшийся ассимилирующий

лист, 6 - верхушечная почка побега с листовыми зачатками

В течение последующих 2,5-3,0 месяцев видимый рост растений прекращался: новые листья не формировались, а уже имеющиеся на побеге постепенно отмирали. В этот период шло накопление листовых зачатков в верхушечной почке главного побега и, к концу 6-го, началу 7-го месяца происходило развитие пяти новых ассимилирующих листьев (рис. 4). Длина черешка у них достигала, в среднем, $2,1 \pm 0,4$ см, длина и ширина листовой пластин- ки $(1,0 \pm 0,1$ и $0,6 \pm 0,0$ см, соответственно). Метамеры, в узлах которых развивались новые листья, были меньшего диаметра (до $0,07 \mathrm{~cm}$ ), по сравнению с ранее сформированными. В базальной части побега наблюдали отмирание и перегнивание части ранее сформированных метамеров. Новые придаточные корни не развивались. К концу 7-го месяца растения отмирали.

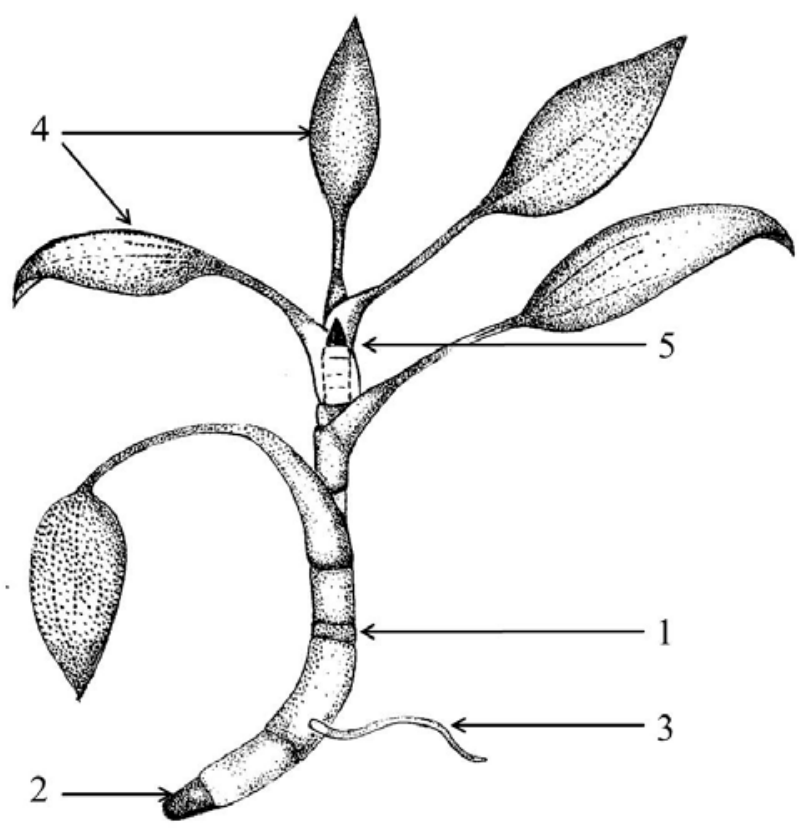

Рис. 4. Ювенильное растение C. palustrus на завершающем этапе развития (конец 6- - начало 7-го мес.): 1 - розеточный побег, 2 - отмирающий участок розеточного побега (главный корень и гипокотиль отмерли), 3 - вновь сформированный придаточный корень, 4 - развернувшиеся ассимилирующие листья, 5 - верхушечная почка с листовыми зачатками

На этой стадии развитие растения прекращалось, онтогенез в лабораторных условиях обрывался. В рамках онтоморфогенеза рассмотренные этапы онтогенетического развития (проросток и ювенильное растение) соответствуют фазе первичного одноосного розеточного побега. Растение в этот период представлено одноосным моноподиально нарастающим побегом закрепления.

\section{Обсуждение}

Исследованная нами ФСП C. palustris, как и у других растений, зависит от целого комплекса эндогенных (генетическое происхождение растений, местоположение цветка и др.) и экзогенных (климатические условия и особенности местообитания) факторов и, в том числе, от эффективности опыления цветков насекомыми. Данный показатель может существенным образом варьировать у соплодий, находящихся в пределах ценопопуляции. Об этом свидетельствуют не только сильно колеблющиеся показатели числа ягод в плотном початковидном соплодии, но и непостоянное число семяпочек в них. Так, в Московской области число семяпочек в ягоде изменяется от 4 до 12 (Efremov and Alekseev, 1983), в то время как в Кировской - 5-9 (Vishnitskaya, 2009). В составе плотных початковидных соплодий у C. palustris могут располагаться ягоды, число сформировавшихся семян в которых может достигать 13 , так и ягоды, в которых семена не развиваются вообще. Последние нередко можно обнаружить как в нижней, так и в верхней части соплодия, иногда такие ягоды располагаются в виде скоплений в средней части початковидного соплодия. По-видимому, определенные трудности с опылением у C. palustris обусловлены колебаниями уровня воды в естественных местообитаниях вида в течение всего периода развития. На опыление цветков насекомыми также, по нашему мнению, может влиять и затененность мест произрастания некоторых популяций. По данным А. П. Ефремова и 
Ю. Е. Алексеева (Efremov and Alekseev, 1983), на одном соплодии C. palustris число семян может достигать 350-400 штук, что не противоречит и полученным нами данным. Так, нами были обнаружены единичные соплодия, число семян в которых достигало 327-405 штук. Между тем, в плотном соплодии число образованных семян, в среднем, достигает 164,0 $\pm 89,3$ штук, что в два раза меньше по сравнению с приведенными выше величинами. Вполне вероятно, что произрастание в береговой зоне затопления, отмелях, озерных сплавинах, топких берегах водоемов, вынуждает растение тратить большие энергетические ресурсы на поддержание вегетативной сферы, вследствие чего семенная продуктивность может понижаться.

По классификации А. Martin (1946 - цит. по: Crocker and Barton, 1955) зародыш в зрелых семенах мы относим к разделу III (семена с осевым расположением зародыша), типу А (семена с удлиненным зародышем). Особый интерес вызывает тот факт, что зародыш белокрыльника, находящийся в семени, уже содержит хлорофилл (Dudley, 1937). Такая особенность рассматривается рядом исследователей (Hohryakov, 1975) как прогрессивный признак, коррелирующий с гидрофилией. Кроме того, это способствует общей тенденции к ускорению развития растений (Hohryakov, 1975). Не случайно проростки белокрыльника уже в первый год своего развития формируют нормально развитый участок розеточного побега, способный пережить неблагоприятное время года. Отметим также, что недолговечность главного корня проростка, по мнению L. Boyd (1932 - цит. по: Didley, 1937) является признаком «прогрессивной морфологии» («advanced morphology», ibid), в отличие от простой трубчатой семядоли, которая рассматривается как «примитивная особенность» («primitive characteristic», Didley, 1937). Еще одной важной чертой, заслуживающей внимания, является отсутствие корневых волосков на главном и придаточном корнях проростка белокрыльника. При этом в семействе Araceae наблюдается большая вариабельность в формировании корневых волосков, например, Pistia не образует корни; Acorus, Orontium и Peltandra формируют корни с корневыми волосками (Shannon, 1953).

Согласно нашим наблюдениям и данным Vishnitskaya (2009), свежесобранные семена C. palustris не прорастают. Однако наличие прорастания, даже при коротком периоде ВХС, говорит о том, что семена белокрыльника находятся в состоянии неглубокого физиологического покоя, обусловленного физиологическим механизмом торможения ( $\mathrm{B}_{1}$ - тип покоя по: Nikolaeva et al., 1999). Такой тип покоя преодолевается под действием различных факторов (например, холодная стратификация, сухое хранение и др., Nikolaeva et al., 1999), что подтверждается как нашими экспериментами, так и данными других исследователей (Guppy, 1897 - по: Hutchinson, 1975; Dudley, 1937; Vishnitskaya, 2009).

В экспериментальных условиях нами получены достаточно высокие величины лабораторной всхожести семян белокрыльника. Надо иметь в виду, что такая «лабораторная экология дает лишь приблизительное представление об экологии прорастания того же вида в природе» (Levina, 1981, p. 61). Даже в условиях, наиболее приближенных к природным (прорастание в грунте в оранжерее), всхожесть семян этого вида имеет сравнительно низкие значения: 36,0 $\pm 11,9 \%$ (van Leeuwen et al., 2014).

Репродуктивный успех, при поддержании благоприятного состояния ценопопуляции, не ограничивается только способностью семян к прорастанию. Немаловажную роль здесь играет способность растений, развивающихся из генеративных диаспор, к выживанию, особенно на первых этапах своей жизни. Так, согласно Н. Г. Солоневич (1954 - цит. по: Vishnitskaya, 2009), проростки C. palustris встречаются в природе часто и в небольшом числе и, как правило, на покрытом водой грунте. На наличие в природных условиях немногочисленных проростков белокрыльника указывал и Eber (1983). Однако Vishnitskaya (2009), наблюдая популяции белокрыльника болотного в Кировской обл., подвергает эти данные сомнению. Нами на изучаемых водоемах проростки этого растения не обнаружены. При этом мы находили единичные растения в виргинильном возрастном состоянии. В группировке взрослых особей эти растения, как правило, находились в очень разреженных местах при высоком уровне освещенности. По-видимому, в плотных популяциях проростки, как правило, не способны выжить. Однако в естественных условиях семенное возобновление C. palustris все же возможно.

Длительная экспозиция проростков большинства видов водных растений в чашках Петри с последующим перемещением в аквариумы завершается их гибелью. Это подтверждает точку зрения Mahlin (1984), отмечавшего, что содержание культуры растений из вод умеренного пояса в аквариумах - процесс достаточно сложный. Не являются исключением и молодые растения С. palustris, которые обычно, в этом случае, не доживают до стадии пяти и более листьев (Dudley, 1937; Efremov and Alekseev, 1983; Vishnitskaya, 2009). Именно поэтому в литературе не описано ювенильное возрастное состояние.

В связи с тем, что, в нашем случае, на ювенильной стадии развитие растения прекращалось, мы так же, как и Vishnitskaya (2009), считаем онтогенез особей генеративного происхождения в лабораторных условиях обрывающимся. Основным способом размножения у белокрыльника является специализированное вегетативное размножение, осуществляемое за счет обламывания корневищ и боковых вегетативных почек (Efremov and Alekseev, 1983; Vishnitskaya, 2009; Sarneel, 2013). Однако, несмотря на то, что многие растения могут размножаться вегетативным путем и распространяться в новую среду обитания без образования семян (Pan and Price, 2001), формирование семян по-прежнему остается чрезвычайно важным (van Leeuwen et al., 2014).

\section{Заключение}

Наши исследования свидетельствуют о достаточно высоком показателе фактической семенной продуктивности у C. palustris в исследуемом регионе. Сочетание этого показателя с высокой лабораторной всхожестью семян после непродолжительного периода влажной холодной стратификации, которую семена так же проходят в естественных условиях, свидетельствует, с одной стороны, о высоком показателе репродуктивного успеха вида и, соответственно, о высокой жизнеспособности этого растения в рамках его ареала и в разных условиях обитания популяции. С другой стороны, критическим моментом в семенной репродукции белокрыльника болотного является собственно оплодотворение, успешность которого в отдельных случаях может быть очень низка, несмотря на нормальное функционирование репродуктивных органов.

В лабораторных условиях онтогенез особей генеративного происхождения обрывающийся. В естественных местообитаниях оптимальными условиями для прорастания и развития проростков являются переходные сообщества, в которых затененные участки сочетаются с хорошо освещенными. Однако редкость встреч в популяциях молодых растений генеративного происхождения связана, по-видимому, с массовой гибелью особей в течение прегенеративного периода онтогенеза. Основными лимитирующими факторами в данном случае выступают освещенность, колебания уровня воды и глубина произрастания. Несмотря на возможность развития растений в природных условиях из генеративной диаспоры, основным способом размножения C. palustris является вегетативное, характерное для большинства водных и прибрежноводных растений.

\section{References}

Barabé, D., \& Labrecque, M. (1983). Vascularisation de la fleur de Calla palustris (Araceae). Canadian Journal of Botany, 61, 1718-1726.

Barrett, S. C. H. (2010). Understanding plant reproductive diversity. Philosophical Transactions of the Royal Society B: Biological Sciences, 365, 99-109.

Belyakov, E. A., \& Lapirov, A. G. (2015). Fruit germination of some representatives of the family Sparganiaceae Rudolphi under laboratory conditions. Inland Water Biology, 8(1), 33-37.

Cabrera, L. I., Gerardo, A. S., Chase, M. W., Mayo, S. J., Bogner, J., \& Dávila, P. (2008). Phylogenetic relationships of aroids and duck-weeds (Araceae) inferred from coding and noncoding plastid DNA. American Journal of Botany, 95(9), 1153-1165. 
Crocker, W., \& Barton, L. V. (1955). Fiziologiya semyan [Physiology of seeds]. Izdatelstvo Inostrannoy Literatury, Moscow (in Russian).

Cusimano, N., Bogner, J., Mayo, S. J., Boyce, P. C., Wong, S. Y., Hesse, M., Hetterscheid, W. L. A., Keating, R. C., \& French, J. C. (2011). Relationships within the Araceae: Comparison of morphological patterns with molecular phylogenies. American Journal of Botany, 98(4), 654-668.

Dudley, M. G. (1937). Morphological and cytological studies of Calla palustris. Botanical Gazette, 98(3), 556-571.

Eber, W. (1983). Untersuchungen zur Populationsbiologie von Calla palustris L. Tuexenia, 3, 417-421 (in German).

Efremov, A. P., \& Alekseev, Y. E. (1983). Belokrylnik bolotnyy (Calla palustris). Biological Flora of the Moskow Region, 7, 67-82 (in Russian).

Godefroid, S., van de Vyver, A., \& Vanderborght, T. (2010). Germination capacity and viability of threatened speciescollections in seed banks. Biodiversity and Conservation, 19, 1365-1383.

Henriquez, C. L., Arias, T., Pires, J. C., Croat, T. B., \& Schaal, B. A. (2014). Phylogenomics of the plant family Araceae. Molecular Phylogenetics and Evolution, 75, 91-102.

Hlyzova, N. Y. (2011). Belokrylnik bolotnyy - Calla palustris L. In: Krasnaya kniga Voronezhskoy oblasti. T. 1. Rasteniya. Lishayniki. Griby [The Red Book of the Voronezh Oblast. Vol. 1. Plants. Lichens. Fungi]. Modek, Voronezh (in Russian).

Hohryakov, A. P. (1975). Somaticheskaya ehvolyuciya odnodol'nyh [Somatic evolution of monocots]. Nauka, Moscow (in Russian).

Hutchinson, G. E. (1975). A treatise on limnology. Volume 1. Geography, physics, and chemistry. John Wiley \& Sons, Inc., New York.

Kalamees, R., \& Zobel, M. (2002). The role of the seed bank in gap regeneration in a calcareous grassland community. Ecology, 83(4), 1017-1025.

Lapirov, A. G., Belyakov, E. A., \& Lebedeva, O. A. (2017). Biomorphology and rhythm of seasonal development of the relic species Lobelia dortmanna in oligotrophic lakes of Tver region. Regulatory Mechanisms in Biosystems, 8(3), 349-355 (in Russian).

Levina, R. E. (1981). Reproduktivnaya biologiya semennyh rasteniy [Reproductive biology of seed plants]. Nauka, Moscow (in Russian).

Mahlin, M. D. (1984). Po alleyam gidrosada [Along the alleyways of the hydroside]. Gidrometeoizdat, Leningrad (in Russian).

Nauheimer, L., Metzler, D., \& Renner, S. S. (2012). Global history of the ancient monocot family Araceae inferred with models accounting for past continental positions and previous ranges based on fossils. New Phytologist, 195, 938-950.
Nikolaeva, M. G., Lyanguzova, I. V., \& Pozdova, L. M., (1999). Biologiya semyan [Biology of Seeds]. NII Khimii St. Peterburg Gos. Univ., St. Petersburg (in Russian).

Nilsson, C., Brown, R. L., Jansson, R., \& Merritt, D. M. (2010). The role of hydrochory in structuring riparian and wetland vegetation. Biological Reviews, 85(4), 837-858.

Nugroho, B. T. A., \& Santika, Y. (2008). Exploration and inventory of Araceae genera in Silui Mountain and Uluisimbone Forest, Kolaka Regency, SouthEast Sulawesi. Biodiversitas, 9(4), 288-291.

Pan, J. J., \& Price, J. S. (2001). Fitness and evolution in clonal plants: The impact of clonal growth. Evolutionary Ecology, 15(4-6), 583-600.

Rudskiy, I. V., Titova, G. E., \& Batygina, T. B. (2011). Analysis of spacetemporal symmetry in the early embryogenesis of Calla palustris L., Araceae. Mathematical Modelling of Natural Phenomena, 6(2), 82-106.

Sameel, J. M. (2013). The dispersal capacity of vegetative propagules of riparian fen species. Hydrobiologia, 710, 219-225.

Savinykh, N. P., \& Cheryomushkina, V. A. (2015). Biomorphology: Current status and prospects. Contemporary Problems of Ecology, 8(5), 541-549.

Scribailo, R. W., \& Tomlinson, P. B. (1992). Shoot and floral development in Calla palustris (Araceae - Calloideae). International Journal of Plant Sciences, 153(1), 1-13.

Shannon, E. L. (1953). The production of root hairs by aquatic plants. The American Midland Naturalist, 50(2), 474-479.

Silanteva, M. M. (2016). Calla palustris L. - Belokrylnik bolotnyy. In: Krasnaya kniga Altayskogo kraya. T. 1. Redkie i nahodyashchiesya pod ugrozoy ischeznoveniya vidy rasteniy i gribov [Red Book of the Altai territory. Vol. 1. Rare and endangered species of plants and fungi]. Izdatelstvo Altayskogo Universiteta, Barnaul (in Russian).

Ulrich, S., Hesse, M., Broderbauer, D., Bogner, J., Weber, M., \& Halbritter, H. (2013). Calla palustris (Araceae): New palynological insights with special regard to its controversial systematic position and to closely related genera. Taxon, 62, 701-712.

van Leeuwen, C. H. A., Sarneel, J. M., van Paassen, J., Rip, W. J., \& Bakker, E. S. (2014). Hydrology, shore morphology and species traits affect seed dispersal, germination and community assembly in shoreline plant communities. Journal of Ecology, 102, 998-1007.

Vishnitskaya, O. N. (2009). Biomorfologiya nekotoryh splavinoobrazuyushchih gigrogelofitov [Biomorphology of some floating mat-forming hygrogelophytes]. Syktyvkar (in Russian). 